\title{
Emotional Presence in a Relationship of Inquiry: The Case of One-to-One Online Math Coaching
}

\author{
Stefan Stenbom and Stefan Hrastinski \\ KTH Royal Institute of Technology \\ Martha Cleveland-Innes \\ Athabasca University and KTH Royal Institute of Technology
}

\begin{abstract}
Emotions have been confirmed to be a critical component of the process of learning. In the online Community of Inquiry theoretical framework, and the recently suggested online Relationship of Inquiry framework, emotions are considered a subsection of social presence. In this study, the concept of emotional presence is examined. This examination occurs within the Relationship of Inquiry framework, developed to analyze one-to-one online coaching. A survey of online coaches and a transcript coding procedure from the online coaching service Math Coach provide the data for the study. The results indicate that a Relationship of Inquiry framework consisting of cognitive, social, teaching, and emotional presence enhances the exploration of one-to-one online coaching settings. The interpretation of these results identifies emotional presence as an essential and distinct part of one-to-one online math coaching.
\end{abstract}

\section{Introduction}

Research about human emotions can be found across several fields of study, from the medical neurosciences to the social behavior sciences. On the side of hard science, new imaging technologies have identified regions of the brain that are activated when particular emotions are experienced (Phan, Wager, Taylor, \& Liberzon, 2004). In social science, Plutchik (2003) argued that emotions exist in the general 
human experience. Therefore, it can be assumed that learners experience multiple different emotions during the process of learning (Brookfield, 2006; Hayashi \& Baranauskas, 2011).

This paper examines the emotional dimension of one-to-one online education. One-to-one online education was, in Hrastinski and Stenbom (2013), conceptualized as online coaching. In online coaching, an individual gets support from a coach in order to achieve an educational goal. Theoretically, this learning activity is grounded in collaborative constructivism, where a coach is promoting the higher order thinking of a coachee through the process of inquiry (Stenbom, 2015). The learning process has earlier been analyzed by adapting the Community of Inquiry framework (Garrison, Anderson, \& Archer, 2000) to a Relationship of Inquiry for analysis of one-to-one online coaching (Stenbom, Hrastinski, \& Cleveland-Innes, 2012). The empirical case of Stenbom et al. (2012) was a program called Math Coach, where online coaching was performed using chat and a shared digital whiteboard. In Math Coach, practically all conversations included a considerable emotional aspect, where emotional words and emoticons were used as a part of the learning process. This emotional aspect was, despite its notable presence in the learning process, only captured as a minor part of the social aspect of learning in the framework.

This paper examines the role of emotions in the Relationship of Inquiry framework. First, the literature about emotions, as it relates to learning and the framework, is reviewed. Second, an empirical study is reported in which the emotional element of learning is tested using a survey and a transcript coding procedure. Finally, the paper discusses the role of emotions in the Relationship of Inquiry framework.

\section{Literature Review}

\section{Emotions and Learning}

The role of emotion-perhaps with the exception of anxiety-has been largely ignored in the research about learning (Dirkx, 2008; Schutz \& Lanehart, 2002; Värlander, 2008). In spite of this lack of scholarly interest, it is unreasonable to assume that something as integral and ubiquitous in the human experience as emotion could be absent in an online learning environment. The authors of this paper, therefore, do not argue whether emotions are present in learning. Instead, we focus on how emotions emerge in the learning situation.

To guide the conceptualization of emotions and learning, Pekrun, Goetz, Titz, and Perry (2002) introduced the term academic emotions "for emotions that are directly linked to academic learning, classroom instruction, and achievement” (p. 92). Academic emotions are emotions related to the student experience. This conceptualization aligns well with studies confirming emotions as a critical component of the learning process (Dirkx, 2008; Sutton, 2004; Sutton \& Wheatley, 2003).

Differences between emotions expressed in face-to-face communication and in computermediated communication were reviewed in Derks, Fischer, and Bos (2008). They identify two differences: reduced visibility and anonymity. Reduced visibility relates to the idea that emotional communication, to a large extent, is based on nonverbal cues, such as facial expression or accentuation, which are lacking in an online environment. In order to enhance visibility online, abbreviations, special words, and symbols are common. A common set of symbols consists of emoticons, which can indicate an emotion. An emoticon can, for example, serve the same role as a nonverbal cue to intensify or tone down an expression (Lee \& Wagner, 2002; Walther \& D'Addario, 2001). Anonymity refers to the notion that a participant in online interaction can feel less known than in a face-to-face conversation. Evidence that it is easier for strangers to express feelings in Internet therapy than in face-to-face settings is an example of the effect of this anonymity (McKenna, Green, \& Gleason, 2002). 


\section{The Community of Inquiry Framework}

The Community of Inquiry (CoI) is a conceptual framework grounded in collaborative constructivism for the analysis of online learning environments (Garrison, 2013; Garrison et al., 2000). It is built on the notion of a community of inquiry as introduced in Peirce (1955) and put into an educational context by Lipman (1991). It is considered the most prominent framework for analyses of online learning (Akyol et al., 2009; Jézégou, 2010; Swan \& Ice, 2010). The original Community of Inquiry framework consists of three interdependent elements: cognitive, teaching, and social presence. These are illustrated in Figure 1.

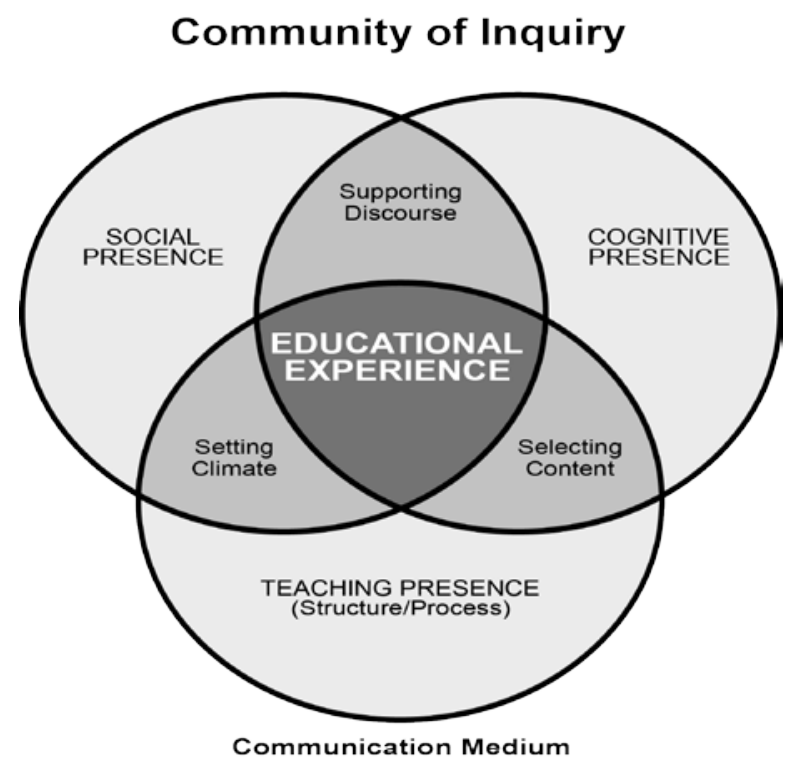

Figure 1. Community of Inquiry. Garrison et al. (2000). Used with permission.

Cognitive presence is "the extent to which learners are able to construct and confirm meaning through sustained reflection and discourse” (Garrison, Anderson, \& Archer, 2001, p. 11). Teaching presence is "the design, facilitation, and direction of cognitive and social processes for the purpose of realizing personally meaningful and educationally worthwhile learning outcomes” (Anderson, Rourke, Garrison, \& Archer, 2001, p. 5). Social presence was first defined as the ability of learners to project themselves socially and emotionally in a community of inquiry (Rourke, Anderson, Garrison, \& Archer, 2001) but has since been redefined as "the ability of participants to identify with the community (e.g., course of study), communicate purposefully in a trusting environment, and develop inter-personal relationships by way of projecting their individual personalities” (Garrison, 2009, p. 352).

Each element of the Community of Inquiry framework has subsets called categories. All categories reflect an aspect of cognitive, teaching, or social presence. The categories in cognitive presence include triggering event, exploration, integration, and resolution; teaching presence includes design and organization, facilitation, and direct instruction; and social presence includes personal/affective, open communication, and group cohesion.

In order to analyze a learning environment using the framework, two main methods have been employed. These are the 34-item Community of Inquiry framework survey instrument (Arbaugh et al., 2008; Swan et al., 2008) and the Community of Inquiry transcript coding procedure (Garrison et al., 2000; Garrison, Cleveland-Innes, Koole, \& Kappelman, 2006). 
The basic structure of the Community of Inquiry framework has persisted since its introduction, but some modifications have been suggested. One modification is a proposal that the framework should include a learning presence. This presence reflects planning, monitoring, adapting strategies, and reflections on results (Shea \& Bidjerano, 2010; Shea et al., 2014). Another suggested modification is to add an element reflecting the emotional aspect of learning. This element is named emotional presence (Cleveland-Innes \& Campbell, 2012).

\section{Emotional Presence}

The aspect of emotion was, in the original version of Community of Inquiry framework, considered a category within social presence called emotional expression. It was defined as "the ability and confidence to express feelings related to the learning experience" (Garrison et al., 2000, p. 99). In Rourke et al. (2001) the emotional expression category was replaced by a personal/affective category that included the use of humor, self-disclosure, and expression of emotions. In a recent study, the position of emotions in the Community of Inquiry was assessed. Cleveland-Innes and Campbell (2012) called for a new element in the Community of Inquiry named emotional presence. In their definition, emotional presence is "the outward expression of emotion, affect, and feeling by individuals and among individuals in a community of inquiry, as they relate to and interact with the learning technology, course content, students, and the instructor” (Cleveland-Innes \& Campbell, 2012, p. 283). This definition was presented both theoretically and empirically. They argue that, theoretically, the importance of emotions has been reduced in the transfer from Lipman's (2003) face-to-face community of inquiry to Garrison et al.'s (2000) online community of inquiry. To empirically test this new element, six additional items were added to the original 34-item Community of Inquiry framework survey instrument. An exploratory factor analysis with 217 participants studying 19 courses in different fields revealed a fourth emotional factor. This exploratory study also called for further research confirming or rejecting their findings. Following this, Garrison (2013) reports, "After a decade of research into the community of inquiry theoretical framework, it would appear that affective responses may not be the defining characteristics of social presence” (p. 107).

\section{The Relationship of Inquiry Framework}

Stenbom et al. (2012) introduced the Relationship of Inquiry framework. It is an adaption of the Community of Inquiry to a one-to-one online coaching setting. The relationship is a conceptual connection that is built between two persons who engage in critical discourse. It is argued that the theoretical framework of the Community of Inquiry by Garrison et al. (2000) offers a structure needed for analyzing the complexities of online learning not only for groups but also for dyads.

The Relationship of Inquiry framework, as described in Stenbom et al. (2012), contains the same elements as those in the Community of Inquiry (cognitive, teaching, and social presence) with modified definitions reflecting the one-to-one learning setting. Cognitive presence is the intellectual processing of the student being coached, who is the coachee, based on the practical inquiry model (Garrison et al., 2001). Social presence is the interaction, outside the subject at hand, which outlines the interpersonal relationship. Teaching presence is the work of the coach in order to establish and maintain a relationship of inquiry. The categories from the Community of Inquiry are also utilized with modified definitions. The categories for cognitive presence are triggering event, exploration, integration, and resolution; for social presence, personal/affective, open communication, and relationship cohesion; and for teaching presence, design and organization, facilitation, and direct instruction.

\section{Aim and Research Questions}

The aim of this paper is to examine the role of emotions in the Relationship of Inquiry framework. This is accomplished by evaluating Cleveland-Innes and Campbell's (2012) suggestion that emotions may exist as a separate element in the Community of Inquiry. The study is guided by the following questions: 
1. To what extent does emotional presence emerge in an online relationship of inquiry?

2. How does emotional presence correlate with the demographic characteristics of coaches?

3. How does emotional presence intersect with the other presences?

\section{Method}

\section{Research Setting}

The setting for this study was the Math Coach program. The Math Coach program provides students with mathematics help using online coaching. In the program, text-based chat and a shared digital whiteboard are used. The software was specially designed for Math Coach and is based on Microsoft Lync, with additional features, such as a cue and archiving. The service is open during weekday evenings throughout the school year. Coachees are students aged 12-19, and coaches are university students studying to become teachers. There is a preparatory course for coaches provided before they enter the program. The Math Coach program is a joint activity of four universities in three cities in Sweden. All students in the age group from the (currently) 15 municipalities that are sponsors can use the service. Within the program, more than 18,000 conversations have taken place so far. All conversations are archived.

\section{Design and Procedure}

In this case study, analysis of two data collections has been performed. These data collections are a survey study and a quantitative content analysis.

Survey study. The survey study was done using the Relationship of Inquiry survey instrument, developed by Stenbom et al. (2012) through the modification of the 34-item Community of Inquiry framework survey instrument (Arbaugh et al., 2008; Swan et al., 2008). Five emotional presence items from Cleveland-Innes and Campbell (2012) were reformulated to a one-to-one context (see Table 4). These items were then included to form a 39-item survey instrument. One item from Cleveland-Innes and Campbell (2012) was excluded, since that item applied to communities but not a one-to-one context.

The survey was distributed to all coaches active in the Math Coach program in spring 2012. Data were collected about the coaches and their perception of cognitive, teaching, social, and emotional presence in their interactions with coachees. The data for cognitive, teaching, and social presence has been previously presented in Stenbom et al. (2012), while the emotional presence data are new. The survey was completed by all active coaches $(N=41)$. Demographic characteristics are presented in Table 1. The variable "Age group of future students" states the orientation of the coaches' teacher programs. The age groups align with how schools in Sweden are organized by grade. Coaches had, on average, 120 hours of experience working as a math coach and had completed $70 \%$ of their teacher training.

Table 1

Demographic Characteristics of Participants in the Survey Study

\begin{tabular}{|c|c|c|c|}
\hline & & $N$ & $\%$ \\
\hline \multirow[t]{2}{*}{ Gender } & Female & 20 & 49 \\
\hline & Male & 21 & 51 \\
\hline \multirow[t]{3}{*}{ Location } & Karlstad & 7 & 17 \\
\hline & Linköping & 16 & 39 \\
\hline & Stockholm & 18 & 44 \\
\hline \multirow[t]{3}{*}{ group } & future7-12 & 7 & 17 \\
\hline & $13-15$ & 9 & 22 \\
\hline & $16-19$ & 25 & 61 \\
\hline
\end{tabular}


Quantitative content analysis. The coding instrument was built on Garrison et al. (2000) and Garrison et al. (2006). The coding procedure used in this paper was issued in Stenbom, Jansson, and Hulkko (in press), but a separate detailed analysis of the transcript coding focusing on emotional presence was done for the present study.

The coding template consisted of cognitive, teaching, social, and emotional presence. For each of the elements, two to four categories were used. The element of emotional presence used in this study was constructed with three categories: activity emotions, outcome emotions, and directed affectiveness. The process of identifying these categories included preliminary transcript investigation and scrutiny of the survey. The categories were then justified in a discussion with the coaches. The first two categories, activity emotions and outcome emotions, are both task related and are built on the control-value theory of achievement emotions (Pekrun, 2006; Pekrun et al., 2002). Activity emotions refer to the ongoing process and content of the conversation, while outcome emotions refer to the expectancy or outcome value of the coaching session. Pekrun (2006) divides outcome emotions into prospective and retrospective emotions. Initial coding did not support this division, so the distinction was left out of the analysis. The third category, directed affectiveness, is the recognition and sharing of emotions or moods between the two individuals in the relationship. This category also deals with the lack of nonverbal emotional cues in textbased communication (Derks et al., 2008; Rourke et al., 2001). The coding scheme is displayed in the appendix.

A total of 60 conversations were randomly selected - 10 per age group-from the year 2012. For all conversations, both the coach and coachee provided informed consent. The coding procedure was performed by two persons and involved three steps: coding training, independent coding, and reliability calculation. First, the coders were trained to perform the coding using trial documents and by discussing the scheme. Second, the coders independently coded 30 conversations each. Finally, the reliability was calculated using 10 randomly selected conversations coded by both coders. The unit of analysis was a complete "message." This unit of analysis was chosen because preliminary coding revealed that a message relates to one or a few of the categories of the scheme. The intersections between elements and categories were included in the coding by enabling a message to be coded with more than one category. A message coded with one category was assigned a value of 1 for that category. For messages coded with two categories, each category was allocated a value of 0.5 . Those with three categories were assigned a value of 0.33 . No messages were coded with more than three categories.

\section{Results}

This section presents the findings of the study. First, the reliability of the data is reviewed. Then, the emergence of emotional presence is reported at the element level in comparison with cognitive, teaching, and social presence, followed by the findings at the item and category levels. Lastly, the correlation between the demographic characteristics of the coaches and the intersection of the elements is presented.

\section{Reliability}

Survey study. The reliability of the emotional presence items in the survey was measured as internal consistency of scales using Cronbach's (1951) alpha. A calculated value of $\alpha=0.74$ for emotional presence indicates an acceptable level of internal consistency (Nunally \& Bernstein, 1987). The survey scale was a 5-point Likert scale ( 1 = strongly disagree to 5 = strongly agree).

Quantitative content analysis. The reliability of the coding procedure was measured using percent agreement and Cohen’s (1960) kappa (De Wever, Schellens, Valcke, \& Van Keer, 2006). A total of 10 conversations, consisting of 665 coding decisions, were coded by two persons. These conversations 
had a percent agreement of 0.89 for the elements and 0.74 for the categories. For Cohen's (1960) kappa, values of 0.84 for the elements and 0.71 for the categories were calculated.

\section{Element Level}

Survey study. The mean and standard deviation for each presence in the Relationship of Inquiry survey instrument was examined. The values are presented in Table 2.

A comparison between the mean values per respondent was done in order to investigate the differences between elements. A Kruskal-Wallis test showed significant difference between the elements, $\chi^{2}(3, N=164)=15.83, p<0.01$. Post hoc comparisons using pairwise Mann-Whitney tests indicated that coaches rated emotional presence lower than cognitive presence $(U=601.50, p=0.03)$, social presence ( $U=532.00, p<0.01)$, and teaching presence $(U=457.00, p<0.01)$. There are no other significant differences among elements.

Table 2

The Mean and Standard Deviation for Each Element in the Survey

\begin{tabular}{lll}
\hline Element & $M$ & $S D$ \\
\hline Cognitive presence & 3.83 & 0.79 \\
Teaching presence & 4.00 & 0.79 \\
Social presence & 3.91 & 0.82 \\
Emotional presence & 3.50 & 1.07 \\
\hline
\end{tabular}

Quantitative content analysis. In Table 3, the means and standard error of means for elements are displayed per conversation. The table is organized so that it displays both messages sent by the coach and the coachee separately as well as, when applicable, the sum of their messages—noted as "Both." In the same table, the total sum of codes is also presented.

Since the same entities took part in all conversions, a repeated one-way ANOVA test with Bonferroni post hoc analysis was chosen to guide the analysis. Significant differences were found between the elements, Wilks' lambda $=0.73, F(3,57)=7.22, p<0.01$. The post hoc analysis found no difference between cognitive presence and teaching presence and no difference between social and emotional presence. The difference between cognitive presence and teaching presence compared to social and emotional presence was, on the other hand, significant. In summary, the content analysis shows that cognitive presence and teaching presence are more common than social and emotional presence.

Table 3

Means and Standard Error of Means for Elements Per Conversation and Total Sum of Codes

\begin{tabular}{lllll}
\hline Elements & Sender & $M$ & $S E$ & Total codes \\
\hline Cognitive presence & Coachee & 16.53 & 2.15 & 991.67 \\
Teaching presence & Coach & 15.63 & 2.02 & 937.67 \\
Social presence & Coach & 4.58 & 0.60 & 275.00 \\
& Coachee & 4.76 & 0.68 & 285.67 \\
Emotional presence & Coth & 9.34 & 1.23 & 560.67 \\
& Coach & 5.57 & 0.87 & 334.33 \\
All elements & 4.74 & 0.73 & 284.67 \\
& Both & 10.32 & 1.49 & 619.00 \\
& Coach & 25.78 & 3.11 & 1547.00 \\
& Coachee & 26.03 & 3.12 & 1562.00 \\
& Both & 51.82 & 6.15 & 3109.00 \\
\hline
\end{tabular}




\section{Item and Category Level}

Survey study. In Table 4, the means and standard deviations are displayed for the emotional presence items. A Kruskal-Wallis test showed significant differences between the survey questions, $\chi^{2}(4$, $N=204)=45.45, p<0.01$. Post hoc comparisons using the Mann-Whitney test indicated significant differences between all questions except between EMO2 and EMO3.

Table 4

Items in the Emotional Presence Element of the Survey

\begin{tabular}{llrll}
\hline Item & Question & $N$ & $M$ & $S D$ \\
\hline EMO1 Emotion is expressed by students during coaching. & 41 & 4.17 & 0.92 \\
EMO2 Expressing emotion in relation to math coaching is40 & 3.75 & 0.95 \\
EMO3 I acknowledged emotion expressed by students during41 & 3.73 & 0.87 \\
EMO4 In my role as coach, I demonstrate emotion online during41 & 3.05 & 0.95 \\
EMO5 I find myself responding emotionally about problems or41 & 2.78 & 1.06 \\
issues that come up during coaching. & & & \\
\hline
\end{tabular}

Quantitative content analysis. In order to further investigate emotional presence, the data representing the three emotional presence categories was investigated. Messages including emotional presence were found in 59 of the 60 conversations examined. Examples from the dataset, translated from Swedish by the authors, can be found in Table 5 .

Table 5

Examples of Emotional Presence from Conversations

\begin{tabular}{|c|c|c|c|c|}
\hline Elements & Sender & Message & Log & Line \\
\hline \multirow[t]{2}{*}{ Activity emotion } & Coachee & $\begin{array}{l}\text { I don't understand anything about } \\
\text { this. NFI! All I know is that it } \\
\text { involves negative numbers. }\end{array}$ & 46 & 73 \\
\hline & Coach & I will gladly help you! :-) & 27 & 37 \\
\hline \multirow[t]{2}{*}{ Outcome emotion } & Coachee & $\begin{array}{l}\text { I have a test in percent next week, } \\
\text { what do you think I should do? :-S :-S }\end{array}$ & 17 & 4 \\
\hline & Coach & $\begin{array}{l}\text { I am very sorry but our time is up for } \\
\text { today :-(. Can you come back } \\
\text { tomorrow? }\end{array}$ & 22 & 63 \\
\hline \multirow[t]{2}{*}{$\begin{array}{l}\text { Directed } \\
\text { affectiveness }\end{array}$} & Coachee & $\begin{array}{l}\text { You are my hero! :-) Thank you for } \\
\text { helping me! }\end{array}$ & 25 & 72 \\
\hline & Coach & Bravo! & 59 & 45 \\
\hline
\end{tabular}

Table 6 shows the means and standard error of means for the three categories per conversation. Three separate repeated one-way ANOVA tests with Bonferroni post hoc analysis were performed to compare the emotional presence categories. For all three cases of the coach's emotions (Wilks' lambda $=0.59$, $F(2,58)=20.20, p<0.01$ ), the coachee's emotions (Wilks' lambda $=0.61, F(2,58)=18.28, p<0.01$ ), and emotions expressed by both persons (Wilks' lambda $=0.56, F(2,58)=22.57, p<0.01$ ), there are significant differences between all three categories. 
Table 6

Means and Standard Error of Means for Categories in Emotional Presence Per Conversation and Total Sum of Codes

\begin{tabular}{lllll}
\hline Emotional categories Sender & $M$ & $S E$ & Total codes \\
\hline Activity emotion & Coach & 3.37 & 0.61 & 202.00 \\
& Coachee & 2.98 & 0.50 & 179.00 \\
Outcome emotion & Both & 6.35 & 1.06 & 381.00 \\
& Coach & 0.11 & 0.06 & 6.33 \\
& Coachee & 0.09 & 0.06 & 5.50 \\
Directed & Both & 0.20 & 0.11 & 11.83 \\
& Coach & 2.10 & 0.32 & 126.00 \\
& Coachee & 1.67 & 0.30 & 100.17 \\
& Both & 3.77 & 0.53 & 226.17
\end{tabular}

The measures of emotional presence presented by the coach and by the coachee were also compared using paired-sample $t$-tests for all conversations. No significant difference was found for any of the emotional categories: activity emotions $-t(59)=1.15, p=0.26$; outcome emotions $-t(59)=0.56, p=$ 0.58 ; and directed affectiveness $-t(59)=1.32, p=0.19$. In addition, no significant differences were found at the element level: $t(59)=1.42, p=0.16$.

\section{Association With Demographic Characteristics}

Any relationship between the emotional presence of the coaches and their demographic characteristics presented in Table 1 was tested using the survey. These tests revealed no significant differences. A Mann-Whitney $U$ test showed no significant difference between emotion and gender, $U=$ 196.50, $p=0.72$. Kruskal-Wallis tests showed no significant difference between emotion and location, $\chi^{2}(2, N=41)=0.35, p=0.84$, or between emotion and the educational stage of the coach's future students, $\chi^{2}(2, N=41)=1.04, p=0.60$. Correlation tests with Spearman's rho showed no significant correlation between emotion and work experience, $r_{S}(41)=-0.12, p=0.45$, or between emotion and the completed part of teacher training, $r_{S}(41)=0.26, p=0.10$.

\section{Intersections With Other Elements}

In order to evaluate the position of emotions, intersections between emotional presence and other elements are of interest. Out of the 3,109 messages in the quantitative content analysis, 2,241 messages were coded with one element, 832 were coded with two elements, and 36 were coded with three elements. The number of double-coded messages including emotional presence was 480 . Out of the 36 triple-coded messages, 30 included emotional presence. The intersections between emotional presence and the other elements are listed in Table 7 and Table 8.

Table 7

Number of Double-Coded Elements Including Emotional Presence

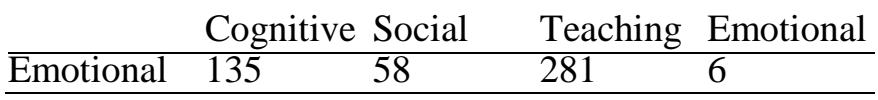

Table 8

Number of Triple-Coded Elements Including Emotional Presence

\begin{tabular}{lllll} 
& \multicolumn{2}{l}{ Cognitive Social } & Teaching & Emotional \\
\hline Cognitive & 1 & & & \\
Social & 4 & 1 & & \\
Teaching & 0 & 19 & 2 & 0 \\
Emotional & 0 & 3 & 0 & 0 \\
\hline
\end{tabular}




\section{Discussion}

The purpose of this paper is to examine the role of emotions in online coaching. This rests on the assumption that emotion is an essential element of the process of learning (Pekrun et al., 2002). However, the role of emotions in theoretical frameworks has not been sufficiently researched (Artino, 2012; Garrison, 2013). Cleveland-Innes and Campbell (2012) propose that emotional presence may exist as an overlapping element in the online Community of Inquiry theoretical framework. In the present study, emotional presence is evaluated in the one-to-one Relationship of Inquiry framework using the Math Coach program. A survey of coaches and subsequent quantitative content analysis were used to collect data.

\section{The Emergent Role of Emotional Presence}

The dataset indicates that emotional presence is a natural part of a four-element framework for the analysis of one-to-one online coaching. Abbreviations, special words, and symbols, such as emoticons, are used regularly to enhance the communication of emotion between the coach and coachee. The transcript coding procedure revealed that emotional presence is as common as social and teaching presence when an entire conversation is evaluated. In the survey, coaches rated emotional presence as evident but less evident than cognitive, social, and teaching presence. Questions about emotions in general were reported as more prominent than questions about the emotion of the coach, and the coaches specifically pointed out that they rarely expressed their own emotion. Following Plutchik (2003) and Phan et al.'s (2004) assertions that emotions exist in all experience, it can be hypothesized that coaches experience several emotions during coaching but use the reduced visibility offered by online communication in order to modify their own emotions to show only the emotions they feel support the learning process. This hypothesis needs to be investigated in future research.

No differences between the measures of emotional presence expressed by the coach and coachee were found. This provides evidence that emotions are as common for the coach as for the coachee.

The suggested categories for emotional presence were activity emotion, outcome emotion, and directed affectiveness. In the dataset, only two categories - activity emotion and directed affectivenesswere clearly present, while outcome emotion was almost absent. Nonetheless, when we were developing the categories, informal discussions we had with coaches suggested that outcome emotions, such as anxiety about an upcoming test, are common in Math Coach conversations.

\section{Association With Demographic Characteristic}

Previous studies have found that factors such as experience and gender have an impact on the expression of emotions in learning (Derks et al., 2008). This was not the case in this study. No variations based on gender, location, educational stage of future students, work experience, or completed part of teacher training was found. This indicates that each member of the team of coaches has a similar approach to how emotional presence is supported in the learning process.

\section{Intersections With Other Elements}

Understanding the intersection between and among presences may enrich both theoretical and practical insights into online learning (Kozan \& Richardson, 2014). In order to analyze the role of emotional presence, and particularly its relation to social presence, this intersection is of interest. Of the messages that were coded with more than one element, emotional presence was the most used. For double-coded messages, a combination of emotional presence and teaching or cognitive presence was often used. For triple-coded messages, combinations of emotional presence with teaching and social presence were more common than other combinations. Combinations of emotional presence and social presence were only sporadic. The fact that emotions intersect with cognitive and teaching presence outside of social presence supports the detaching of emotions from social presence. 


\section{Limitations and Future Research}

Measuring emotions is a problematic task that "brings significant epistemological, ontological, theoretical and practical challenges” (Rienties \& Rivers, 2014, p. 1); therefore, this early study has several limitations.

The data source had a high level of reliability. The survey study had an internal consistency measured as a Cronbach's (1951) alpha of 0.74 for emotional presence. The coding procedure had a percent agreement of 0.89 for elements and 0.74 for categories. For the coding procedure, a Cohen's (1960) kappa of 0.84 for elements and 0.71 for categories also support this. The data source of this study is, however, limited to 41 coaches' perceptions of Math Coach as reported in the survey and to a quantitative content analysis of 3,109 messages in Math Coach. In order to make more general conclusions about emotional presence, larger survey studies and studies in other learning environments are needed. This study used two recognized methods for data collection-survey and quantitative content analysis. There are differences between the extents of emotional presence revealed by the two methods. This variation may be a result of the difference between the coaches' perceptions of emotions in learning, as reported in the survey, and the expressed emotions in the dialogue, as measured through the quantitative content analysis. The differences between the instruments need to be investigated before a general statement of their validity can be claimed. This process should involve a review of both the survey and the quantitative content analysis. The suggested categories of emotional presence need to be further evaluated with a special focus on outcome emotion, as it was almost absent in the current study. The categories also need to be aligned with the survey, which currently lacks that breakdown.

The concept of emotional presence has the potential to enhance frameworks for analyzing online learning. This premise is based on the evidence that emotions are an important factor in learning, although previously they were considered nothing more than a way of projecting the personality of an individual. In this study, a framework of cognitive, social, teaching, and emotional presences provides new, more detailed insight into the learning activity within online coaching. In order to validate the element of emotional presence, further research is needed. The questions for the survey and the templates for transcript coding need to be validated in large studies and in various settings.

\section{Conclusion}

In this paper, the role of emotional presence in online coaching has been examined. The findings support the premises that (1) emotional presence exists in an online Relationship of Inquiry, and (2) emotional presence can be measured outside of social presence. The dataset from the Math Coach program supports the notion that a Relationship of Inquiry framework consisting of cognitive, social, teaching, and emotional presences does enhance the exploration of one-to-one online coaching settings. It is suggested that emotional presence exists as a separate element within the Relationship of Inquiry model. The proposed definition is that emotional presence is the outward expression of emotion, affect, and feeling in a relationship of inquiry. The three categories of activity emotion, outcome emotion, and directed affectiveness are suggested to form the element. In further research, the absence of outcome emotion in our dataset should be explored as a component of emotional presence.

\section{About the Authors}

Dr. Stefan Stenbom obtained his $\mathrm{PhD}$ in 2015 and is a lecturer in online learning at KTH Royal Institute of Technology, Stockholm. His research involves exploring one-to-one online education. For more information, see http://www.stefanstenbom.se. 
Dr. Stefan Hrastinski is professor at KTH Royal Institute of Technology, Sweden. His research focuses on online learning and collaboration in educational and organizational settings.

Dr. Martha Cleveland-Innes is professor and chair in the Center for Distance Education at Athabasca University in Alberta, Canada. Her current research interests are in the areas of leadership in open and distance higher education, online teaching and learning, and the effects of emotion on learning. She is currently Guest Professor of Technology-Enhanced Learning at KTH Royal Institute of Technology in Stockholm, Sweden.

\section{Author Note}

The authors want to thank Malin Jansson and Annelie Hulkko for their work performing the coding procedure for this paper.

Correspondence concerning this article should be addressed to Stefan Stenbom, Department for Learning, School of Education and Communication in Engineering Science, KTH Royal Institute of Technology, SE-100 44 Stockholm, Sweden. E-mail: stkn@kth.se, Tel.: +46 87906129.

\section{References}

Akyol, Z., Arbaugh, J. B., Cleveland-Innes, M., Garrison, D. R., Ice, P., Richardson, J. C., \& Swan, K. (2009). A response to the review of the Community of Inquiry framework. The Journal of Distance Education/Revue de l'Éducation à Distance, 23(2), 123-136.

Anderson, T., Rourke, L., Garrison, D. R., \& Archer, W. (2001). Assessing teaching presence in a computer conferencing context. Journal of Asynchronous Learning Networks, 5(2), 1-17.

Arbaugh, J. B., Cleveland-Innes, M., Diaz, S. R., Garrison, D. R., Ice, P., Richardson, J. C., \& Swan, K. P. (2008). Developing a community of inquiry instrument: Testing a measure of the community of inquiry framework using a multi-institutional sample. The Internet and Higher Education, 11(3), 133-136.

Artino, A. R., Jr. (2012). Emotions in online learning environments: Introduction to the special issue. The Internet and Higher Education, 15(3), 137-140.

Brookfield, S. D. (2006). The skillful teacher: On technique, trust, and responsiveness in the classroom. San Francisco: Jossey-Bass.

Cleveland-Innes, M., \& Campbell, P. (2012). Emotional presence, learning, and the online learning environment. The International Review of Research in Open and Distance Learning, 13(4), 269292.

Cohen, J. (1960). A coefficient of agreement for nominal scales. Educational and Psychological Measurement, 20(1), 37-46.

Cronbach, L. J. (1951). Coefficient alpha and the internal structure of tests. Psychometrika, 16(3), 297334. 
De Wever, B., Schellens, T., Valcke, M., \& Van Keer, H. (2006). Content analysis schemes to analyze transcripts of online asynchronous discussion groups: A review. Computers \& Education, 46(1), 6-28.

Derks, D., Fischer, A. H., \& Bos, A. E. (2008). The role of emotion in computer-mediated communication: A review. Computers in Human Behavior, 24(3), 766-785.

Dirkx, J. M. (2008). The meaning and role of emotions in adult learning. New Directions for Adult and Continuing Education, 2008(120), 7-18.

Garrison, D. R. (2009). Communities of inquiry in online learning. In P. L. Rogers, G. A. Berg, J. V. Boettcher, C. Howard, L. Justice, \& K. D. Schenk (Eds.), Encyclopedia of distance learning (2nd ed.). Hershey: IGI Global.

Garrison, D. R. (2013). Theoretical foundations and epistemological insights of the Community of Inquiry. In Z. Akyol \& D. R. Garrison (Eds.), Educational communities of inquiry: Theoretical framework, research and practice (pp. 1-11). Hershey: IGI Global.

Garrison, D. R., Anderson, T., \& Archer, W. (2000). Critical inquiry in a text-based environment: Computer conferencing in higher education. Internet and Higher Education, 2(2-3), 87-105.

Garrison, D. R., Anderson, T., \& Archer, W. (2001). Critical thinking, cognitive presence, and computer conferencing in distance education. American Journal of Distance Education, 15(1), 7-23.

Garrison, D. R., Cleveland-Innes, M., Koole, M., \& Kappelman, J. (2006). Revisiting methodological issues in transcript analysis: Negotiated coding and reliability. The Internet and Higher Education, 9(1), 1-8.

Hayashi, E. C., \& Baranauskas, M. C. C. (2011). The affectibility concept in systems for learning contexts. International Journal for e-Learning Security (IJeLS), 1(1/2), 10-18.

Hrastinski, S., \& Stenbom, S. (2013). Student-student online coaching: Conceptualizing an emerging learning activity. The Internet and Higher Education, 16, 66-69.

Jézégou, A. (2010). Community of Inquiry in E-learning: A critical analysis of Garrison and Anderson model. Journal of Distance Education/Revue De L'Éducation à Distance, 24(3), 1-18.

Kozan, K., \& Richardson, J. C. (2014). Interrelationships between and among social, teaching, and cognitive presence. The Internet and Higher Education, 21, 68-73.

Lee, V., \& Wagner, H. (2002). The effect of social presence on the facial and verbal expression of emotion and the interrelationships among emotion components. Journal of Nonverbal Behavior, 26(1), 3-25.

Lipman, M. (1991). Thinking in education (1st ed.). New York: Cambridge University Press.

Lipman, M. (2003). Thinking in education (2nd ed.). New York: Cambridge University Press.

McKenna, K. Y., Green, A. S., \& Gleason, M. E. (2002). Relationship formation on the Internet: What's the big attraction? Journal of Social Issues, 58(1), 9-31.

Nunally, J. C., \& Bernstein, I. H. (1987). Psychometric theory. New York: McGraw-Hill. 
Peirce, C. S. (1955). The fixation of belief. In C. S. Peirce \& J. Buchler (Eds.), Philosophical writings of Peirce. Mineola: Courier Dover Publications.

Pekrun, R. (2006). The control-value theory of achievement emotions: Assumptions, corollaries, and implications for educational research and practice. Educational Psychology Review, 18(4), 315341.

Pekrun, R., Goetz, T., Titz, W., \& Perry, R. P. (2002). Academic emotions in students’ self-regulated learning and achievement: A program of qualitative and quantitative research. Educational Psychologist, 37(2), 91-105.

Phan, K. L., Wager, T. D., Taylor, S. F., \& Liberzon, I. (2004). Functional neuroimaging studies of human emotions. CNS Spectrums, 9, 258-266.

Plutchik, R. (2003). Emotions and life: Perspectives from psychology, biology, and evolution. Washington, DC: American Psychological Association.

Rienties, B., \& Rivers, B. (2014, December 10). Measuring and understanding learner emotions: Evidence and prospects. Learning Analytics Review.

Rourke, L., Anderson, T., Garrison, D. R., \& Archer, W. (2001). Assessing social presence in asynchronous text-based computer conferencing. Journal of Distance Education/Revue De L’Éducation à Distance, 14(2).

Schutz, P. A., \& Lanehart, S. L. (2002). Introduction: Emotions in education. Educational Psychologist, 37(2), 67-68.

Shea, P., \& Bidjerano, T. (2010). Learning presence: Towards a theory of self-efficacy, self-regulation, and the development of a communities of inquiry in online and blended learning environments. Computers \& Education, 55(4), 1721-1731.

Shea, P., Hayes, S., Uzuner-Smith, S., Gozza-Cohen, M., Vickers, J., \& Bidjerano, T. (2014). Reconceptualizing the Community of Inquiry framework: Exploratory and confirmatory analysis. The Internet and Higher Education, 23, 9-17.

Stenbom, S. (2015). Online coaching as a Relationship of Inquiry: Exploring one-to-one online education (Doctoral thesis). KTH Royal Institute of Technology, Stockholm.

Stenbom, S., Hrastinski, S., \& Cleveland-Innes, M. (2012). Student-student online coaching as a Relationship of Inquiry: An exploratory study from the coach perspective. Journal of Asynchronous Learning Networks, 16(5), 37-48.

Stenbom, S., Jansson, M., \& Hulkko, A. (in press). Revising the Community of Inquiry framework for the analysis of one-to-one online learning relationships. The International Review of Research in Open and Distributed Learning.

Sutton, R. E. (2004). Emotional regulation goals and strategies of teachers. Social Psychology of Education, 7(4), 379-398.

Sutton, R. E., \& Wheatley, K. F. (2003). Teachers' emotions and teaching: A review of the literature and directions for future research. Educational Psychology Review, 15(4), 327-358. 
Swan, K., \& Ice, P. (2010). The Community of Inquiry framework ten years later: Introduction to the special issue. The Internet and Higher Education, 13(1-2), 1-4.

Swan, K., Richardson, J. C., Ice, P., Garrison, D. R., Cleveland-Innes, M., \& Arbaugh, J. B. (2008). Validating a measurement tool of presence in online communities of inquiry. E-mentor, 2(24), 112.

Walther, J. B., \& D’Addario, K. P. (2001). The impacts of emoticons on message interpretation in computer-mediated communication. Social Science Computer Review, 19(3), 324-347.

Värlander, S. (2008). The role of students' emotions in formal feedback situations. Teaching in Higher Education, 13(2), 145-156. 


\section{Appendix}

The Relationship of Inquiry Coding Scheme

\begin{tabular}{|c|c|c|c|}
\hline Element & Category & $\begin{array}{l}\text { Indicators (examples } \\
\text { only) }\end{array}$ & Examples \\
\hline \multirow[t]{4}{*}{$\begin{array}{l}\text { Cognitive } \\
\text { presence }\end{array}$} & Triggering event & $\begin{array}{l}\text { Stating a problem, } \\
\text { changing direction }\end{array}$ & $\begin{array}{l}\text { "Here’s the problem: ..." } \\
\text { "I have another issue.” }\end{array}$ \\
\hline & Exploration & $\begin{array}{l}\text { Brainstorming, } \\
\text { broad search for } \\
\text { insights, } \\
\text { information exchange }\end{array}$ & $\begin{array}{l}\text { "Perhaps I could use...” } \\
\text { "Am I thinking right } \\
\text { here?" } \\
\text { "What is a square root?" }\end{array}$ \\
\hline & Integration & $\begin{array}{l}\text { Connecting ideas, } \\
\text { computations }\end{array}$ & $\begin{array}{l}\text { "I can combine ... with } \\
\text { ".." } 7 / 12-x=1 / 4 "\end{array}$ \\
\hline & Resolution & $\begin{array}{l}\text { Achieve solution, } \\
\text { analysis of solution, } \\
\text { implementation }\end{array}$ & $\begin{array}{l}\text { "The answer is 3!" } \\
\text { "I made a mistake } \\
\text { with..." } \\
\text { "Then the apple is } \\
\text { cheaper..." }\end{array}$ \\
\hline \multirow[t]{3}{*}{$\begin{array}{l}\text { Teaching } \\
\text { presence }\end{array}$} & $\begin{array}{l}\text { Design and } \\
\text { organization }\end{array}$ & $\begin{array}{l}\text { Establishing } \\
\text { interaction, } \\
\text { setting parameters for } \\
\text { the inquiry }\end{array}$ & $\begin{array}{l}\text { "What can I help you } \\
\text { with?" } \\
\text { "You can type in the text } \\
\text { box or draw on the } \\
\text { whiteboard." }\end{array}$ \\
\hline & $\begin{array}{l}\text { Facilitating } \\
\text { discourse }\end{array}$ & $\begin{array}{l}\text { Stimulating } \\
\text { constructive inquiry, } \\
\text { assessing process }\end{array}$ & $\begin{array}{l}\text { "Do you have an idea?" } \\
\text { "What answer did you } \\
\text { get?” }\end{array}$ \\
\hline & Direct instruction & $\begin{array}{l}\text { Providing steps to } \\
\text { solution, summarizing } \\
\text { the discussion }\end{array}$ & $\begin{array}{l}\text { "You should multiply } \\
\text { with } 10 . " \\
\text { " } 1 / 3+1 / 4=4 / 12+3 / 12 "\end{array}$ \\
\hline Social presence & $\begin{array}{l}\text { Open } \\
\text { communication } \\
\text { Relationship } \\
\text { cohesion }\end{array}$ & $\begin{array}{l}\text { Acknowledging, } \\
\text { trivial expressions } \\
\text { Greetings, vocatives, } \\
\text { building links }\end{array}$ & $\begin{array}{l}\text { “Okay!”, “Perfect.” } \\
\text { “I can’t see the figure.” } \\
\text { “Hello.”, “Good luck.” } \\
\text { "What should we do } \\
\text { now?” }\end{array}$ \\
\hline \multirow[t]{3}{*}{$\begin{array}{l}\text { Emotional } \\
\text { presence }\end{array}$} & Activity emotion & $\begin{array}{l}\text { Emotion about the } \\
\text { inquiry }\end{array}$ & "We solved it!! :-)" \\
\hline & Outcome emotion & $\begin{array}{l}\text { Emotion about the } \\
\text { consequence of the } \\
\text { inquiry }\end{array}$ & $\begin{array}{l}\text { "Gah! I have a test on } \\
\text { Monday that I will fail if } \\
\text { I don't get this." }\end{array}$ \\
\hline & $\begin{array}{l}\text { Directed } \\
\text { affectiveness }\end{array}$ & $\begin{array}{l}\text { Emotion towards the } \\
\text { other person }\end{array}$ & $\begin{array}{l}\text { “Thank you for helping } \\
\text { me!” } \\
\text { “;-)”, “:-(“ , “:-P” }\end{array}$ \\
\hline
\end{tabular}

